\title{
Toward a political theory of the emergence of environmental incentive regulation
}

\author{
Marcel Boyer* \\ and \\ Jean-Jacques Laffont**
}

This article makes some steps toward a formal political economy of environmental policy. Economists' quasi-unanimous preference for sophisticated incentive regulation is reconsidered. We recast the question of instrument choice in the general mechanism design literature within an incomplete contract approach to political economy. We show why "constitutional" constraints on the instruments of environmental policy may be desirable, even though they appear inefficient from a standard economic viewpoint. Their justification lies in the limitations they impose on the politicians' ability to distribute rents. Insights are provided on the emergence of incentive mechanisms in environmental regulation.

\section{Introduction}

- A large number of instruments have been considered to regulate polluting activities: Pigouvian taxes, quotas, subsidies for pollution reduction, marketable emission permits, ${ }^{1}$ deposit refund systems (see Bohm (1981)), assignments of legal liabilities, ${ }^{2}$ etc. As a result, the choice of policy instruments has become one of the major questions debated in environmental economics. Cropper and Oates (1992) devote a large part of their survey to this question. See also Segerson (1996) and Lewis (1996). Most of the discussion has taken place within the benevolent social maximizer paradigm. Starting with Buchanan and Tullock (1975), the necessity of looking for political economy explanations of the choice of instruments has been recognized. ${ }^{3}$ However, dissatisfaction remains. Hahn

* CIRANO, École Polytechnique de Montréal, University of Montreal; boycrm@cirano.umontreal.ca.

** IDEI and GREMAQ, Université de Toulouse I, France; laffont@cict.fr.

We would like to thank Tracy Lewis, Patrick González, Larry Jones, two anonymous referees, Editor Glenn Ellison, and participants in the Canadian Economic Theory Conference (Toronto 1997), Boston College 1997 Microeconomic Workshop, GREEN-CIRANO Conference on the Environment (Québec 1997). and Econometric Society Meeting (Chicago 1998) for their comments. Financial suppost from the Social Science and Humanities Research Council (Canada) and the Mattei Foundation (Italy) is gratefully acknowledged.

${ }^{1}$ Crocker (1966) and Dales (1968a, 1968b) first proposed marketing emission permits.

2 There is a large literature on this topic; see in particular Segerson (1995) and Boyer and Laffont (1996, 1997) and the references therein. See also Gupta, Van Houtven, and Cropper (1996) for an empirical analysis of EPA's decisions on the cleanup of Superfund sites.

${ }^{3}$ Beyond the debate about the Buchanan-Tullock article (Yohe, 1976; Dewees, 1983; and Coelho, 1976), see also Boyer (1979). Noll (1983), McCubbins, Noll, and Weingast (1989), Hahn (1990), and Hahn and McGartland (1989). 
(1990) writes: "There is yet no satisfactory theory about the emergence of incentive based mechanisms" (p. 22). Lewis (1996) concludes his survey as follows: "I see the next progression in [environmental regulation] as being a positive analysis asking which kind of environmental policies will be implemented under information and distribution constraints when special interests try to intervene to affect policy" (p. 844).

The purpose of this article is to provide some preliminary steps in the construction of a formal political economy of environmental economics (see also Laffont (1996)). Economists' general preferences for sophisticated incentive mechanisms is reconsidered in a political economy approach resting on two main features: private information of economic agents, which explains the rents accruing to them as functions of policy choices, and the incomplete contract nature of constitutions, which explains the need for politicians as residual decision makers.

Incomplete information is by now well understood as being a major obstacle to first-best efficient regulation. Starting with Loeb and Magat (1979), regulation of natural monopolies has been modelled as a principal-agent problem. When contracting is unconstrained, the revelation principle then states that any type of regulation is equivalent to a revelation mechanism. (See also Baron and Myerson (1982) and Guesnerie and Laffont (1984).) In such a mechanism, agents communicate truthfully their private information to the regulator, who then recommends proper actions. The requirement of incentive compatibility puts constraints on the actions that can be implemented.

It is only recently that this framework has been extensively developed for environmental economics. ${ }^{+}$A revelation mechanism can be viewed as a command and control instrument and yet is clearly optimal here: once an optimal revelation mechanism has been obtained, the question of its implementation by various economic instruments or institutions, such as regulatory proceedings, taxes, and markets, arisesbut by definition those institutions then implement the same allocation as the command and control approach (see Laffont (1994) for an example).

In such a framework the question of instrument choice is empty. Such a question often arose in the literature because authors were not careful enough in defining their instruments. For example, Yohe (1976) correctly shows that the alleged difference between quotas and price controls in Buchanan and Tullock (1975) disappears when instruments are appropriately defined. He writes: "When the equivalent quantity control is properly specified, both the economist's general preference for taxation and the regulatee's general preference for quotas will disappear" (p. 981).

Two types of meaningful comparisons of instruments are then possible. In the first type, one considers constraints on instruments (the analysis should explain the origin of these constraints), and various constrained instruments can be compared. This is the essence of Weitzman's (1975) comparison of prices and quantities in a situation where asymmetric information calls for nonlinear prices as optimal instruments, as Roberts and Spence (1976) pointed out. Another example is the case of nonconvexities due to negative externalities. (See Starrett (1972) and Baumol and Bradford (1972).) There, quotas are equivalent to nonlinear taxes. Pigouvian (linear) taxes are then dominated by quotas. Similarly, taxes and subsidies that are equivalent when they are accompanied with appropriate lump-sum transfers differ in their absence with respect to the longrun entry and exit decisions of firms. See Kamien, Schwartz, and Dolbear (1966), Bramhall and Mills (1966), Kneese and Bower (1968), and Dewees and Sims (1976) for further discussion.

+ See Baron (1985a), Laffont (1994), and Lewis (1996). Early applications were essentially reinterpreting Groves mechanisms by treating environmental externalities like public goods. See, for example, Dasgupta. Hammond, and Maskin (1980). 
In the second type, one considers instruments that could be equivalent in the complete contracting framework and introduces imperfections elsewhere in the economy that cannot be corrected by the regulator (then one must give a good explanation of the regulator's inability). This is the case in Buchanan's (1969) example of a polluting monopolist when the subsidies required to correct the monopolistic behavior are not available. Then, the Pigouvian tax is clearly dominated by a quota that implements the second-best tax, as devised for example by Lee (1975) and Barnett (1980), and which depends on the firm's market power.

A systematic analysis of instrument choice should then be conducted in welldefined second-best frameworks, which are all methodological shortcuts of an incomplete contract analysis. Constraints such as limited commitment, renegotiation-proof commitment, collusion, favoritism, and multiprincipal structures' should be considered. Political economy constraints can also be viewed as a special case of this methodology. The lack of finely tuned constitutional control of the politicians (the incomplete contract feature) who have private agendas introduces inefficiencies in the regulatory decision process. It may then become desirable to impose constraints on politicians that favor particular instruments or to force the use of apparently crude instruments.

Section 2 presents the basic model we use, which is a simple model of regulation of a polluting monopolist who is privately informed of the cost of realizing a public project. The asymmetric information about the firm's technology explains that a rent will have to be given up to those who have stakes in the firm. The choice of an environmental policy affects this rent. We derive as a benchmark the environmental policy that maximizes expected social welfare.

Section 3 takes as given the delegation of environmental policy to political majorities. Since the majorities will have different stakes in the informational rent of the firm, the delegation of environmental policy to politicians will enable them to pursue their private agendas, that is, to favor the agents who belong to their majority. As majorities change, this induces an excessive fluctuation of policies. Restricting the instruments used in environmental policy becomes a way to restrict this excessive fluctuation, at the cost of a lack of flexibility. More specifically, we compare the policy consisting in the choice of a single pollution level, a typical command and control regulation, with the policy consisting in the choice of a menu of pollution-transfer pairs, a typical incentive regulation. We determine the conditions under which the higher discretion associated with the second policy is compensated by its greater efficiency potential.

Section 4 explores the foundation of the delegation of environmental policy to politicians. Since a constitution is a rather incomplete contract, a policy choice at the constitutional leve] necessarily has little flexibility. On the contrary, politicians can use their current detailed knowledge of the economy to choose their policy but in so doing will pursue their private agendas. Taking the social cost of public funds-which should be viewed as a proxy for the economic outlook - as the variable that the politicians but not the constitution will be able to make their policy choice contingent on, we characterize the conditions under which the environmental policy conducted by changing majorities is superior to a social-welfare-maximizing but inflexible environmental policy imposed by the constitution.

Section 5 extends the model to a situation where two types of interest groups, stakeholders in the firm and environmentalists, may benefit from the capture of the government through the size of informational rents that the regulation mechanisms

"See Baron ( $198.5 \mathrm{~b})$ for an early study of the distortions due to the uncoordinated activities of two regulators.

(c) RAND 1999. 
leave them. The distortions due to the political process are studied in this more general model, as well as the impact of the dynamics of reelection based on campaign contributions. The comparison of instruments is extended to this case. We find that the competition of interest groups may kill otherwise desirable reforms toward more sophisticated regulation by raising the stakes of political conflict, a kind of negative rentseeking effect. Concluding comments are gathered in Section 6. All proofs are in the Appendix.

\section{The basic model}

- We consider a natural monopoly to which is delegated the realization of a public project that has social value $S$ and $\operatorname{costs} C(\beta, d)$, where $d$ is the level of pollution accompanying the completion of the project and $\beta$ is a cost characteristic that is private information of the firm. For a given pollution level, $\beta$ measures the efficiency of the firm in realizing the project, a higher $\beta$ meaning a higher cost. For a given $\beta$, we assume that allowing more pollution reduces cost.

Two alternative assumptions are then possible on the cost of reducing pollution. The more efficient the firm is, either the more efficient it is in also reducing pollution or the less efficient it is in that regard. In terms of a general cost function $C(\beta, d)$, if we assume $C_{\beta}>0$, we have the choice between $C_{\beta d}<0$ and $C_{\beta d}>0$. We will assume $C_{\beta d}<0$ because, with a one-dimensional asymmetry of information, the positive correlation between ability to produce and ability to reduce pollution seems more compelling than the alternative assumption and leads to more striking results. However, we will point out how our results change with the alternative assumption $C_{\beta d}>0$. To obtain explicit solutions and carry out numerical simulations, we choose a specific cost function corresponding to $C_{\beta d}<0$, namely $C(\beta, d)=\beta(K-d)$, where $K$ is a constant. We assume that $\beta$ can take two values $\{\underline{\beta}, \bar{\beta}\}$, with $\Delta \beta=\bar{\beta}-\underline{\beta}$ and $\nu=\operatorname{Prob}\{\beta=\underline{\beta}\}$.

Let $t$ be the compensatory monetary transfer from the regulator to the firm, which then has a rent equal to

$$
U=t-\beta(K-d)
$$

The social disutility of pollution is $V(d)$ (with $V^{\prime}>0, V^{\prime \prime}>0$ ). If $1+\lambda$, with $\lambda>0$, is the social cost of public funds due to the need for using distortionary taxation to raise public funds, "he consumers' welfare is

$$
C S=S-V(d)-(1+\lambda) t
$$

The utilitarian social welfare is then

$$
W=C S+U=S-V(d)-(1+\lambda) \beta(K-d)-\lambda U .
$$

We assume that $S$ is large enough to make the realization of the project always desirable. Under complete information, a benevolent social welfare maximizer would set $V^{\prime}(d)=(1+\lambda) \beta$ and $t=\beta(K-d)$ to nullify the rent of the firm that is socially costly because $\lambda>0$. The chosen pollution levels would depend on $\lambda$ and $\beta$.

${ }^{6}$ The mean value of $\lambda$ is nonnegligible and considered to be of the order of .3 in developed countries and higher in developing ones. See Jones, Tandon, and Vogelsang (1990) for the empirical evidence. 
Under incomplete information about $\beta$, the firm's individual-rationality and incentivecompatibility constraints must be taken into account. Only the type- $\underline{\beta}$ firm receives a rent that is equal to

$$
\underline{U}=\Delta \beta(K-\bar{d})
$$

where $\bar{d}$ is the pollution level requested from the less efficient type firm by the separating regulation mechanism $((\underline{t}, \underline{d}),(\bar{t}, \bar{d}))$. The firm of type $\underline{\beta}$ can always pretend to be of type $\bar{\beta}$ and realize the project with a pollution level of $\bar{d}$ at a cost of $\beta(K-\bar{d})$; since it is entitled to a transfer $t(K-\bar{d}) \geq \bar{\beta}(K-\bar{d})$, it realizes a profit (rent) of at least $(\bar{\beta}-\beta)(K-\bar{d})$, a decreasing function of $\bar{d}$, which must then be a lower bound on its welfare or profit when it acts according to its real type. (See Laffont and Tirole (1993).) Note that this rent decreases with the pollution level of the inefficient firm. ${ }^{7}$

The optimal pollution levels obtained from the maximization of the expected value of social welfare (1) under the informational constraint on $\beta$ can be characterized by the following program:

$$
\begin{aligned}
\max _{(\underline{d}, \bar{d})} W(\underline{d}, \bar{d})= & {[\nu(S-V(\underline{d})-(1+\lambda) \underline{\beta}(K-\underline{d})-\lambda \dot{\Delta} \beta(K-\bar{d}))} \\
& +(1-\nu)(S-V(\bar{d})-(1+\lambda) \bar{\beta}(K-\bar{d}))]
\end{aligned}
$$

yielding

$$
\begin{aligned}
& V^{\prime}\left(\underline{d}^{*}\right)=(1+\lambda) \underline{\beta} \\
& V^{\prime}\left(\bar{d}^{*}\right)=(1+\lambda) \bar{\beta}+\lambda \frac{\nu}{1-\nu} \Delta \beta .
\end{aligned}
$$

\section{Controlling the discretionary power of politicians through constraints on the choice of instruments}

- We have a continuum [0, 1] of agents in the economy. Let $\alpha$ represent each period the measure of consumers who do not share the firm's rent, the nonstakeholders, and let $1-\alpha$ be the measure of those who share the rent, that is, the stakeholders. Let $\alpha$ be drawn independently each period, taking the value $\alpha^{*} \in(1 / 2,1)$ with probability $1 / 2$ and $1-\alpha^{*}$ with probability $1 / 2$. When $\alpha=\alpha^{*}$, the nonstakeholders majority, of measure $\alpha^{*}$, is in power; when $\alpha=1-\alpha^{*}$, the stakeholders majority is in power and the measure of this majority is also $\alpha^{*}$.

We will assume that politicians have the discretion of using their private information about the economy as exemplified here by the value of $\lambda$, the social cost of public funds, whose distribution is common knowledge but whose value is either observed only by the government (the majority in power) or is commonly observed $e x$ post but cannot be made verifiable by a court. We consider the value of $\lambda$ either to be a proxy for specific economic conditions that the government in power is better

${ }^{7}$ This feature, which follows from our assumptions on the cost function $\left(C_{\beta}>0, C_{\beta d}<0\right)$, will imply that to reduce the costly rent of the efficient firm, one should let pollution increase. However, this striking result would be reversed with the alternative assumptions $\left(C_{\beta}>0, C_{\beta d}>0\right)$ as in $C(\beta, d)=K-d / \beta$, or $\left(C_{\beta}<0, C_{\beta d}<0\right)$ as in $C(\beta, d)=K-\beta d$.

C RAND 1999 
equipped to observe (from confidential reports of the public service bureaucracy, for example) or to refer to complex economic conditions that cannot be written in a constitutional contract. The constitutional convention may, on the other hand, impose constraints on the choice of instruments for pollution abatement.

We want to compare two instruments. The first one is a menu of contracts (abatement levels and associated transfers) offered to the firm. The second one is a single abatement level based on $E \beta$, the expected value of $\beta$, and imposed on both types of firm. The first instrument corresponds to a rather sophisticated incentive regulation of the firm. In the first case, we let the political majorities decide on the menu of abatement levels and transfers; in the second case, they are constrained to a urique level. In each case they can use their private information on $\lambda$.

Let us consider first the sophisticated separating mechanism. If $\alpha=\alpha^{*}$, we have majority 1, which maximizes the welfare of nonstakeholders, who benefit from the project, suffer from the pollution externality, and must pay taxes to finance the realization of the project (the cost of the project plus the rent of the firm), namely

$$
\alpha^{*}(S-V(d)-(1+\lambda) t)=\alpha^{*}(S-V(d)-(1+\lambda) \beta(K-d)-(1+\lambda) U),
$$

thus overestimating in comparison with (1) the social cost of the firm's rent, since $1+\lambda>\lambda .^{8}$ Similarly, if $\alpha=1-\alpha^{*}$, majority 2 maximizes the welfare of stakeholders, who are similar to type 1 agents except that they share the firm's rent, namely

$$
\begin{aligned}
& \alpha^{*}(S-V(d)-(1+\lambda) t)+U \\
& \quad=\alpha^{*}\left(S-V(d)-(1+\lambda) \beta(K-d)-\left(1+\lambda-\frac{1}{\alpha^{*}}\right) U\right),
\end{aligned}
$$

thus underestimating the social cost of the firm's rent, since $1+\lambda-1 / \alpha^{*}<\lambda$. $^{9}$

Majority 1 maximizes over the pollution levels the expected value of the welfare of nonstakeholders given by (4) under incentive and participation constraints of the firm; that is, it solves

$$
\begin{gathered}
\max _{(\underline{d}, \bar{d})} W^{\prime}(\underline{d}, \bar{d})=\alpha^{*}[ \\
\quad \nu(S-V(\underline{d})-(1+\lambda) \underline{\beta}(K-\underline{d})-(1+\lambda) \Delta \beta(K-\bar{d})) \\
+(1-\nu)(S-V(\bar{d})-(1+\lambda) \bar{\beta}(K-\bar{d}))] .
\end{gathered}
$$

Hence

$$
\begin{aligned}
& V^{\prime}\left(\underline{d}_{1}\right)=(1+\lambda) \underline{\beta} \\
& V^{\prime}\left(\bar{d}_{1}\right)=(1+\lambda) \bar{\beta}+(1+\lambda) \frac{\nu}{1-\nu} \Delta \beta,
\end{aligned}
$$

with associated transfers given by $\bar{t}=\bar{\beta}\left(K-\bar{d}_{1}\right)$ and $\underline{t}=\underline{\beta}\left(K-\underline{d}_{1}\right)+\Delta \beta\left(K-\bar{d}_{1}\right)$. Majority 2 similarly maximizes $W^{2}(\underline{d}, \bar{d})$, the expected value of stakeholders given by (5). This leads to

${ }^{8}$ This formulation presumes that the majorities cannot change the funding of firms through indirect taxation that is uniformly spread across all agents.

'We assume that $1+\lambda-1 / \alpha^{*}>0$. Otherwise. we would have to take irito account the agents' individual-rationality constraints, since majority 2 would like to make $U^{\prime}$ as large as possible.

O RAND 1999. 


$$
\begin{aligned}
& V^{\prime}\left(\underline{d}_{2}\right)=(1+\lambda) \underline{\beta} \\
& V^{\prime}\left(\bar{d}_{2}\right)=(1+\lambda) \bar{\beta}+\left(1+\lambda-1 / \alpha^{*}\right) \frac{\nu}{1-\nu} \Delta \beta .
\end{aligned}
$$

We obtain (assuming that each majority is in power half the time) the expected social welfare

$$
E_{\lambda \alpha} W(\underline{d}, \bar{d})=\frac{1}{2} E_{\lambda} W\left(\underline{d}_{1}, \bar{d}_{1}\right)+\frac{1}{2} E_{\lambda} W\left(\underline{d}_{2}, \bar{d}_{2}\right)
$$

where $W\left(\underline{d}_{m}, \bar{d}_{m}\right)$ is the expected level, with respect to the firm's type, of social welfare (1) evaluated at pollution levels chosen by majority $m$ as a function of $\lambda$.

Comparing (3), (7), and (8), we observe that the pollution level of the more efficient firm is optimal whatever the majority in power, since $\underline{d}_{1}=\underline{d}_{2}=\underline{d}^{*}$. But the pollution level of the less efficient firm is either too large (under a nonstakeholders majority government) or too low (under a stakeholders majority government): $\bar{d}_{1}>\bar{d}^{*}>\bar{d}_{2}$. These apparently surprising distortions need some explanation. Since both majorities take fully into account the social cost of pollution $V(d)$, they differ only in their treatment of the informational rent accruing to the stakeholders of the more efficient firm. Majority 1 (nonstakeholders) overvalues the social cost of the firm's informational rent (it uses a weight of $(1+\lambda)$ instead of $\lambda$ ) because it does not share any of that rent. For that majority, the cost of inducing abatement from the less efficient firm, which is the source of the rent of the more efficient firm, is therefore larger than its social cost net of the rent. Majority 1 's regulation leads therefore to a larger-thanoptimal level of pollution from the less efficient firm because it does not value the positive effect of a more stringent abatement level $\bar{d}$ on the efficient firm's rent. On the other hand, majority 2 (stakeholders) undervalues the social cost of the firm's informational rent (it uses a weight of $\left.\left(1+\lambda-1 / \alpha^{*}\right)<\lambda\right)$ because it captures the totality of that rent. For that majority, the net cost of inducing abatement is smaller than its social cost. Majority 2's regulation thus leads to a smaller-than-optimal level of pollution from the less efficient firm.

We now consider the case of a nondiscriminating pollution-abatement mechanism that the constitutional convention may impose on the politicians. The latter then have a more limited discretion for promoting the interests of their constituency. Each majority can now select a single abatement level only, not a menu of pollution abatement and transfer levels.

If the nonstakeholders majority is in power, it now solves

$$
\max _{d} W^{\prime}(d)=\alpha^{*}[S-V(d)-(1+\lambda) E \beta(K-d)-\nu(1+\lambda) \Delta \beta(K-d)],
$$

yielding

$$
V^{\prime}\left(d_{1}\right)=(1+\lambda) E \beta+(1+\lambda) \nu \Delta \beta=(1+\lambda) \vec{\beta}
$$

Similarly, the stakeholders majority chooses a pollution level $d_{2}$ characterized by

$$
V^{\prime}\left(d_{2}\right)=(1+\lambda) E \beta+\left(1+\lambda-1 / \alpha^{*}\right) \nu \Delta \beta=(1+\lambda) \bar{\beta}-\frac{1}{\alpha^{*}} \nu \Delta \beta
$$


Again, $d_{2}<d^{*}<d_{1}$, where $d^{*}$ is the optimal nondiscriminating pollution-abatement level under the same informational constraints. The latter pollution-abatement level solves

$$
\max _{d} W(d)=S-V(d)-(1+\lambda) E \beta(K-d)-\nu \lambda \Delta \beta(K-d),
$$

yielding $V^{\prime}\left(d^{*}\right)=(1+\lambda) E \beta+\lambda \nu \Delta \beta=(1+\lambda) \bar{\beta}-\nu \Delta \beta$.

We obtain an expected social welfare level given by (assuming that each majority is in power half the time)

$$
E_{\lambda \alpha} W(d)=\frac{1}{2} E_{\lambda} W\left(d_{1}\right)+\frac{1}{2} E_{\lambda} W\left(d_{2}\right),
$$

where $W\left(d_{m}\right)$ is the social welfare (1) evaluated at the single pollution level chosen by majority $m$ as characterized by (11) and (12).

The emergence of the separating delegated incentive mechanis $m$ (DIM) hinges on its ex ante comparison with the delegated pooling mechanism (DPM) obtained above. We carry out this comparison for small asymmetries of information represented by $\Delta \beta$.

Proposition 1. For $\bar{\beta}$ close enough to $\underline{\beta}$, we have $E_{\lambda \alpha} W(\underline{d}, \bar{d})>E_{\lambda \alpha} W(d)$, that is, the delegated incentive mechanism chosen by the political majorities dominates the delegated pooling mechanism selected by political majorities if and only if

$$
\operatorname{var}(\lambda)>H\left(\nu, \alpha^{*}, E \lambda\right) \equiv-\nu^{2}\left(\frac{\alpha^{*}-\frac{1}{2}}{\alpha^{* 2}}\right)-1+2 \nu-2(1-\nu) E \lambda-(E \lambda)^{2}
$$

In this context of political delegation, ${ }^{10}$ the emergence of the sophisticated separating incentive mechanisms discriminating between the pollution abatement levels requested from the different firms, will be associated with increases in $E \lambda, v \operatorname{ar}(\lambda)$, and $\alpha^{*}$, and with decreases in $\nu$. A small $\alpha^{*}$ that is close to $\frac{1 / 2}{2}$ corresponds to the case where political agendas differ the most from social welfare; then, pooling is favored to decrease the discretionary pursuit of private agendas. When $E \lambda$ or $\operatorname{var}(\lambda)$ are large, the larger sensitivity of the separating incentive mechanism dominates. Increases in $\nu$ have two effects. A larger $\nu$ implies a strong concern for rents accruing to the firm with probability $\nu$ but also larger distortions from social welfare maximization in the objective function of the majorities, since

$$
\begin{aligned}
& W\left(\underline{d}_{1}, \bar{d}_{1}\right)=\frac{W^{\prime}\left(\underline{d}_{1}, \bar{d}_{1}\right)}{\alpha^{*}}+\nu \Delta \beta\left(K-\bar{d}_{1}\right) \\
& W\left(\underline{d}_{2}, \bar{d}_{2}\right)=\frac{W^{2}\left(\underline{d}_{2}, \bar{d}_{2}\right)}{\alpha^{*}}+\left(1-\frac{1}{\alpha^{*}}\right) \nu \Delta \beta\left(K-\bar{d}_{2}\right) .
\end{aligned}
$$

It turns out that the second distortions are larger and therefore a large $\nu$ favors a nondiscriminating policy (DPM).

${ }^{10}$ Our analysis extends the results of Holmström (1984) on delegation to a ruultiagent framework in which one agent is selected (by a majority rule) and delegated the collective decision within the constraints imposed by the constitution. 
Increases in the asymmetry of information $\Delta \beta$ have a priori an ambiguous effect: the greater ability of discriminating mechanisms to extract rents must be compared with the negative effects of political discretion. However, for a quadratic $V(\cdot)$ function, social welfare is quadratic in $\bar{\beta}$. We can then derive the global superiority of the pooling mechanism or the sophisticated separating mechanism from Proposition 1 and the fact that all welfare levels coincide at $\bar{\beta}=\underline{\beta} \cdot{ }^{.1}$ For more general $V(\cdot)$ functions, the increase in $\bar{\beta}$, which is favorable to letting the majorities choose separating mechanisms, may lead to the superiority of that mechanism over the pooling mechanism even when $\operatorname{var}(\lambda)<H(\cdot)$, that is, even when the pooling mechanism dominates when $\bar{\beta}$ is close to $\beta$. On the other hand, if separation (DIM) dominates for small $\Delta \beta$, it dominates always. Figure 1 provides an example where $\operatorname{var}(\lambda)=0<H(\cdot)=.08$ and yet the separating incentive mechanism chosen by the political majorities dominates the delegated pooling mechanism selected by political majorities when $\bar{\beta}$ is large enough.

Majorities can favor their respective constituency by choosing menus of pollution levels and transfers that maximize their respective welfare functions, yielding the delegated separating incentive regulation regime. Proposition 1 compared this delegation of powers to a constitutional requirement that the majorities select a unique pollution abatement level to be imposed on all firms. One can take a more positive approach to constitutional reform and wonder if moving toward the use of an incentive mechanism with delegated discretion may emerge from unanimous ex ante consent and not simply by appealing to social welfare maximization under the veil of ignorance. For this purpose we can compare ex ante the per-capita welfare of the two types of agents in a DIM and a DPM. We obtain the following proposition.

Proposition 2. For $\bar{\beta}$ close to $\underline{\beta}$, majority 1 prefers the optimal DIM over the optimal DPM if and only if

$$
\operatorname{var}(\lambda)>H^{1}\left(\nu, \alpha^{*}, E \lambda\right) \equiv \frac{1}{2} \frac{\nu^{2}}{\alpha^{* 2}}-1-2 E \lambda-(E \lambda)^{2},
$$

while majority 2 does if and only if

$$
\operatorname{var}(\lambda)>H^{2}\left(\nu, \alpha^{*}, E \lambda\right) \equiv 2 \frac{\nu}{\alpha^{*}}-\frac{1}{2} \frac{\nu^{2}}{\alpha^{* 2}}-1-2\left(1-\frac{\nu}{\alpha^{*}}\right) E \lambda-(E \lambda)^{2} .
$$

Comparing $H^{1}(\cdot), H^{2}(\cdot)$, and $H(\cdot)$, we obtain directly the following corollary, given here without proof.

Corollary 1 . We have

$$
H^{\prime}\left(\nu, \alpha^{*}, E \lambda\right)<H\left(\nu, \alpha^{*}, E \lambda\right)<H^{2}\left(\nu, \alpha^{*}, E \lambda\right)
$$

The nonstakeholders (majority 1) are more active proponents of delegating discretionary power to politicians over environmental policy, that is, of a DIM scheme, than are the stakeholders (majority 2). Majority 1 prefers a DIM scheme as soon as the variance of $\lambda$ reaches the threshold $H^{1}(\cdot)$, while majority 2 will still prefer to stick to the DPM scheme until the variance of $\lambda$ has reached the higher threshold $H^{2}{ }^{2}(\cdot)$. Indeed, the net cost of pollution abatement is higher for majority 1 (because they do not benefit from

${ }^{11}$ The first derivatives of the expected welfare functions with respect to $\bar{\beta}$. evaluated at $\bar{\beta}=\underline{\beta}$, are negative and equal. If $V(d)$ is quadratic, then the second derivatives are independent of $\bar{\beta}$.

(C) RAND 1990 


\section{FIGURE 1}

THE DIFFERENTIAL EXPECTED WELFARE

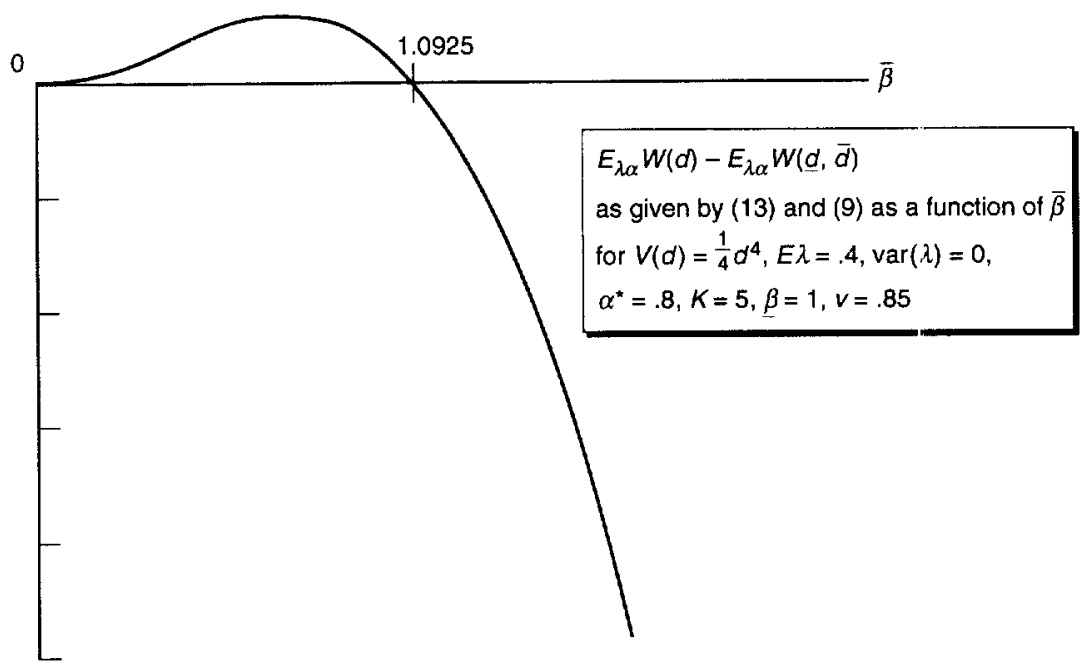

the informational rent of higher abatement) and therefore raises the value of the more efficient pollution-abatement incentive mechanism DIM above that of the cruder DPM as soon as $H^{1}(\cdot)$ is reached. If unanimous approval is needed for constitutional reform in favor of a sophisticated separating incentive mechanism with delegated discretion, it will happen less often than is socially desirable because $H^{2}(\cdot)>H^{\prime}(\cdot)$, that is, because of the resistance of the stakeholders in the firm's rent.

\section{Delegating discretionary power to politicians or not}

- The gain from delegating discretionary power to politicians comes from the use they can make of their information, here their knowledge of $\lambda$, the social cost of public funds. The cost of such delegation is the excessive fluctuation of their decisions $(\underline{d}, \bar{d})$ as a function of $\lambda$, as private agendas are taken into account by successive majorities. Alternatively, the constitutional convention may decide not to delegate such discretionary power but instead impose an incentive mechanism $\left(\left(\underline{t}^{p}, \underline{d}^{p}\right),\left(\bar{t}^{p}, \bar{d}^{p},\right)\right.$ determined at the constitutional level to maximize expected social welfare. This incentive mechanism can be characterized as the solution to the social welfare-maximization program

$$
\begin{aligned}
\max _{(\underline{d}, \bar{d})} W(\underline{d}, \bar{d})= & \nu(S-V(\underline{d})-(1+E \lambda) \underline{\beta}(K-\underline{d})-(E \lambda)\rfloor \beta(K-\bar{d})) \\
& +(1-\nu)(S-V(\bar{d})-(1+E \lambda) \bar{\beta}(K-\bar{d}),
\end{aligned}
$$

yielding

$$
\begin{aligned}
& V^{\prime}\left(\underline{d}^{\prime}\right)=(1+E \lambda) \underline{\beta} \\
& V^{\prime}\left(\bar{d}^{p}\right)=(1+E \lambda) \bar{\beta}+(E \lambda) \frac{\nu}{1-\nu} \Delta \beta .
\end{aligned}
$$

The pollution levels $\underline{d}^{\prime}$ and $\bar{d}^{\prime \prime}$ now depend on $E \lambda$.

C) RAND 1999. 
At the constitutional level, the choice is then between imposing a separating incentive regulation mechanism that maximizes expected social welfare on the basis of the expected value $E \lambda$, a mechanism that we shall call a constitutional incentive mechanism (CIM), or delegating to the political majorities the choice of at separating incentive regulation mechanism that will then be a function of the value of $\lambda$, that is, the delegated incentive mechanism DIM. In the latter case, the choice of pollution-regulation mechanisms will reflect private agendas. The emergence of the latter delegated incentive mechanism, which depends on $\lambda$, hinges on its ex ante comparison with the former constitutional incentive mechanism.

Proposition 3. The difference in expected welfare between the CIM and the DIM converges to zero as $\Delta \beta \rightarrow 0$ and $\operatorname{var}(\lambda) \rightarrow 0$. For a given $\Delta \beta$, the CIM dominates if $\operatorname{var}(\lambda)$ is small. For a given $\operatorname{var}(\lambda)$, the DIM dominates if $\Delta \beta$ is small.

Clearly, the CIM will dominate the DIM chosen by the majorities when the variance of $\lambda$ is small for a given level of asymmetric information, as represented by $\Delta \beta$. Indeed, the CIM is optimal when $\operatorname{var}(\lambda)=0$, whereas the DIM is not. By continuity, for low levels of the variance in $\lambda$, allowing political majorities to use the observed value of $\lambda$ in choosing ex post an incentive mechanism generates little social value but does generate a significant social cost given the pursuit of private agendas. As $\operatorname{var}(\lambda)$ increases, the value of adjusting policies to the realized value of $\lambda$ increases, and therefore it may eventually become better to give political majorities greater latitude in setting policies and choosing the mechanism.

Similarly, the delegation of authority to politicians will be socially valuable and indeed optimal if $\Delta \beta=0$ for a given variance in $\lambda$. By continuity, for small values of $\Delta \beta$, the delegation of authority allows the politicians to fine tune the choice of the incentive mechanism to the realized value of $\lambda$, while the pursuit of their private agendas generates little unwarranted distortions in pollution abatement. Since $\Delta \beta$ is small, maximizing any majority objective function is almost equivalent to maximizing the social welfare function, because there are (almost) no rents. Again, as $\Delta \beta$ increases, for the same given variance of $\lambda$, one expects that the distortions generated by the pursuit of private agendas will eventually exceed the benefit of fine tuning the incentive abatement mechanism chosen by the majorities and will therefore lead to the dominance of the CIM.

\section{Multiple privately informed interest groups}

- In the previous sections we have seen how the delegation of environmental policy to politicians enables them to distribute informational rents to interest groups. In this section we want to explore the extent to which reelection concerns and competing interest groups may mitigate the distortions in the allocation of resources that politicians might find profitable. For this purpose, we extend the model by introducing, in addition to reelection concerns of majorities, first the financing of political coalitions or majorities through campaign contributions, and second an information asymmetry regarding the damages of pollution. In the same way as $\beta$ is private information of stakeholders, the disutility of pollution is now assumed to be $V(\theta, d)$, with $\theta \in\{\underline{\theta}, \bar{\theta}\}, \Delta \theta=\bar{\theta}-\underline{\theta}$, and $\mu=\operatorname{Prob}(\underline{\theta}){ }^{12}$ The parameter $\theta$ is private information of the environmentalists who suffer the pollution damage; we assume that $V_{t}>0$ and $V_{t}>0$. Two assumptions are then possible regarding the value of pollution abatement: either: $V_{t d}>0$ or $V_{t d}<0$. In the first case, the more sensitive the environmentalists are to pollution (larger $\theta$ ),

${ }^{12}$ As for $\beta$, the value of $\theta$ is assumed to be drawn anew every period.

c RAND 1999. 
the less efficient they are in finding ways to reduce their suffering from pollution, and vice versa in the second case. We will assume here that $V_{\theta d}>0$, more precisely that $V(\theta, d)=\theta V(d)$, because it seems more compelling to us and also leads to more striking results.

We maintain our assumption that environmentalists (the new rnajority 1) have no stake in the polluting firm, but we now assume that they will be compensated for the cost of pollution. This compensation assumption should be interpreted as a shortcut reduced-form formulation of a political constraint on the level of hardship that a majority can impose on the agents of the other majority; this assumption can also be interpreted as a threshold under which civil disobedience would be triggered. Since $\theta$ is private information of the environmentalists and since the latter will now be compensated for the cost of pollution, they will be able to capture an informational rent. Together with our assumption $V_{\theta d}>0$, this will lead environmentalists to favor higher pollution levels, which provide them with higher informational rents. Their informational rent is

$$
U_{1}=s-\theta V(d)
$$

where $s$ is the transfer from the government. The stakeholders who do not suffer the pollution damage have an informational rent of

$$
U_{2}=t-\beta(K-d)
$$

The taxpayers, who are now distinct from stakeholders and env ronmentalists, have utility

$$
U_{3}=S-(1+\lambda)(t+s)
$$

The environmentalists of type $\underline{\theta}$ can always pretend to be of type $\bar{\theta}$ and let the government implement the project with a pollution level of $\bar{d}$ at a cost to them of $\underline{\theta} V(\bar{d})$; since they are entitled to a transfer $t(\bar{d}) \geq \bar{\theta} V(\bar{d})$, they then capture a rent of $(\bar{\theta}-\underline{\theta}) V(\bar{d})$, an increasing function of $\bar{d} \cdot{ }^{13}$

Assuming that each group of measure one (environmentalists, stakeholders, taxpayers) represent $1 / 3$ of the population, utilitarian social welfare is

$$
W=U_{1}+U_{2}+U_{3}=S-(1+\lambda)(\beta(K-d)+\theta V(d))-\lambda\left(U_{1}+U_{2}\right) .
$$

Under complete information the optimal pollution is now characterized ${ }^{1+}$ by $\theta V^{\prime}(d)=\beta$. Under incomplete information a revelation mechanism is now a triple $\{d(\beta, \theta), t(\beta, \theta), s(\beta, \theta)\}$. The relevant incentive-compatibility and individual-rationality constraints are, for the stakeholders and the environmentalists respectively,

${ }^{13}$ This feature, which follows from our assumptions $V_{H}>0, V_{d}>0$, and $V_{\text {the }}>0$, will imply that to reduce the costly rent of the less sensitive environmentalists, one should favor a pollution reduction. However, this result would be reversed with the alternative assumptions $\left(V_{H, d}<0\right)$ as in $V(\theta, d)=\theta\left(A+d / \theta^{2}\right)$ with $A>d / \underline{\theta}^{2}$.

${ }^{1+}$ Having an individual-rationality constraint for the environmentalists amounts to and should be interpreted as assuming that they are indemnified at a social cost of $(1+\lambda)$. This is why we now obtain $\theta V^{\prime}(d)=\beta$ instead of $\theta V^{\prime}(d)=(1+\lambda) \beta$.

O RAND 1999. 


$$
\begin{aligned}
E_{\theta}\{t(\underline{\beta}, \theta)-\underline{\beta}(K-d(\underline{\beta}, \theta))\} & \geq E_{\theta}\{t(\bar{\beta}, \theta)-\underline{\beta}(K-d(\bar{\beta}, \theta))\} \\
E_{\theta}\{t(\bar{\beta}, \theta)-\bar{\beta}(K-d(\bar{\beta}, \theta))\} & \geq 0 \\
E_{\beta}\{s(\beta, \underline{\theta})-\underline{\theta} V(d(\beta, \underline{\theta}))\} & \geq E_{\beta}\{s(\beta, \bar{\theta})-\underline{\theta} V(d(\beta, \bar{\theta}))\} \\
E_{\beta}\{s(\beta, \bar{\theta})-\bar{\theta} V(d(\beta, \bar{\theta}))\} & \geq 0 .
\end{aligned}
$$

Assuming Bayesian Nash behavior of stakeholders and environmentalists, the revelation mechanism that maximizes expected social welfare

$$
\left.W(\vec{d})=E_{\mu, \nu}[S-(1+\lambda)(\beta(K-d)+\theta V(d))]-\lambda \mu \underline{U}_{1}-\lambda\right) \underline{\nu} \underline{U}_{2}
$$

under the above incentive- and individual-rationality constraints is characterized by ${ }^{15}$

$$
\begin{aligned}
\underline{\theta} V^{\prime}(d(\underline{\beta}, \underline{\theta})) & =\underline{\beta} \\
\left(\bar{\theta}+\frac{\lambda}{1+\lambda} \frac{\mu}{1-\mu} \Delta \theta\right) V^{\prime}(d(\underline{\beta}, \bar{\theta})) & =\underline{\beta} \\
\underline{\theta} V^{\prime}(d(\bar{\beta}, \underline{\theta})) & =\bar{\beta}+\frac{\lambda}{1+\lambda} \frac{v}{1-\nu} \Delta \beta \\
\left(\bar{\theta}+\frac{\lambda}{1+\lambda} \frac{\mu}{1-\mu} \Delta \theta\right) V^{\prime}(d(\bar{\beta}, \bar{\theta})) & =\bar{\beta}+\frac{\lambda}{1+\lambda} \frac{\nu}{1-\nu} \Delta \beta .
\end{aligned}
$$

Let us assume that the two interest groups use a share of their informational rent as campaign contributions to influence politicians. We consider a two-period model. In period 2, majority 1 is able to favor the interests of environmentalists by maximizing the sum of taxpayers' utility and environmentalists' utility,

$$
W^{1}\left(\overrightarrow{d_{1}}\right)=W\left(\overrightarrow{d_{1}}\right)-\nu \underline{U}_{2},
$$

that is, by not including in its objective function the informational rent of the stakeholders, where $\overrightarrow{d_{1}}=\left(d_{1}(\underline{\beta}, \underline{\theta}), d_{1}(\underline{\beta}, \bar{\theta}), d_{1}(\bar{\beta}, \underline{\theta}), d_{1}(\bar{\beta}, \bar{\theta})\right)$. Similarly, if elected, majority 2 is able to favor the interests of the stakeholders of the firm by maximizing the sum of taxpayers' utility and stakeholders' utility,

$$
W^{2}\left(\overrightarrow{d_{2}}\right)=W\left(\overrightarrow{d_{2}}\right)-\mu \underline{U}_{1},
$$

that is, by not including the informational rent of the environmentalists.

Let us assume that each majority makes campaign contributions $C_{1}$ and $C_{2}$ as a fixed proportion $\zeta$, assumed equal for both majorities, of their average rents: $C_{1}=\zeta \mu \underline{U}_{1}$ and $C_{2}=\zeta \nu \underline{U}_{2}$, with

$$
\underline{U}_{1}=\Delta \theta[\nu V(d(\underline{\beta}, \bar{\theta}))+(1-\nu) V(d(\bar{\beta}, \bar{\theta}))]
$$

and

is On the left appear the adjusted (due to information asymmetry) marginal social values of pollution abatement and on the right the adjusted marginal social costs of pollution abatement in the different cases $(\theta, \beta)$.

O RAND 1999. 


$$
\underline{U}_{2}=\Delta \beta[\mu(K-d(\bar{\beta}, \underline{\theta}))+(1-\mu)(K-d(\bar{\beta}, \bar{\theta}))]
$$

These campaign contributions affect the probability of winning the election that follows. For majority 1 , the probability of winning is assumed to be

$$
\Psi=\frac{1}{2}+\frac{1}{2} g \zeta\left(\mu \underline{U}_{1}-\nu \underline{U}_{2}\right)
$$

where $g$ is a parameter representing the importance of campaign contributions in the electoral process. The stake of winning the election for period 2 is, for majority 1 , $E^{\prime}\left(\overrightarrow{d_{1}}, \overrightarrow{d_{2}}\right)=W^{1}\left(\overrightarrow{d_{1}}\right)-W^{1}\left(\overrightarrow{d_{2}}\right)$ and, for majority $2, E^{2}\left(\overrightarrow{d_{1}}, \overrightarrow{d_{2}}\right)=W^{2}\left(\overrightarrow{d_{2}}\right)-W^{2}\left(\overrightarrow{d_{1}}\right)$. Hence, majority 1 maximizes

$$
W^{1}\left(\overrightarrow{d_{1}}\right)+\delta \Psi E^{1}\left(\overrightarrow{d_{1}}, \overrightarrow{d_{2}}\right)
$$

leading to

$$
\begin{aligned}
\underline{\theta} V^{\prime}\left(\hat{d}_{1}(\underline{\beta}, \underline{\theta})\right) & =\underline{\beta} \\
\left(\bar{\theta}+\frac{\lambda}{1+\lambda} \frac{\mu}{1-\mu} \Delta \theta-\frac{1}{2} \frac{\delta E^{1} g \zeta \Delta \theta \mu}{(1+\lambda)(1-\mu)}\right) V^{\prime}\left(\hat{d}_{1}(\underline{\beta}, \bar{\theta})\right) & =\underline{\beta} \\
\underline{\theta} V^{\prime}\left(\hat{d}_{1}(\bar{\beta}, \underline{\theta})\right)=\bar{\beta} & +\frac{\lambda}{1+\lambda}-\frac{\nu}{1-\nu} \Delta \beta \\
& +\frac{1}{2} \frac{\delta E^{1} g \zeta \Delta \beta \nu}{(1+\lambda)(1-\nu)} \\
\left(\bar{\theta}+\frac{\lambda}{1+\lambda} \frac{\mu}{1-\mu} \Delta \theta-\frac{1}{2} \frac{\delta E^{\prime} g \zeta \Delta \theta \mu}{(1+\lambda)(1-\mu)}\right) V^{\prime}\left(\hat{d}_{1}(\bar{\beta}, \bar{\theta})\right)= & \bar{\beta}+\frac{\lambda}{1+\lambda} \frac{\nu}{1-\nu} \Delta \beta \\
& +\frac{1}{2} \frac{\delta E^{\prime} g \zeta \Delta \beta \nu}{(1+\lambda)(1-\nu)} .
\end{aligned}
$$

Let $\vec{d}_{1}=\left(\hat{d}_{1}(\underline{\beta}, \underline{\theta}), \hat{d}_{1}(\underline{\beta}, \bar{\theta}), \hat{d}_{1}(\bar{\beta}, \underline{\theta}), \hat{d}_{1}(\bar{\beta}, \bar{\theta})\right) .{ }^{16}$ In comparison with the static case, the environmentalist majority increases the pollution levels in all cases, except in the case $(\underline{\beta}, \underline{\theta})$. The reason is that it now wishes not only to decrease, as in the static case, the stakeholders' rent (with respect to the social optimum) because it undervalues this rent in its objective function, but also to increase its own rent in order to increase its probability of winning the election through campaign contributions and furthermore to decrease even further the stakeholders' rent for the same reason.

We obtain symmetric results for the stakeholders majority choosing $\vec{d}_{2}$. In comparison with the static case, the stakeholders majority decreases the pollution levels in all cases except the case $(\underline{\beta}, \underline{\theta})$. The reason is similar to the one for which the environmentalist majority increased the pollution levels. Recalling the social welfare function $W=U_{1}+U_{2}+U_{3}$, let

$$
E_{\lambda \alpha} \hat{\hat{W}}(\overrightarrow{\hat{d}})=\frac{1}{2} E_{\lambda} W\left(\hat{\vec{d}}_{1}\right)+\frac{1}{2} E_{\lambda} W\left(\overrightarrow{\hat{d}_{2}}\right)
$$

\footnotetext{
${ }^{16}$ One should note that the second-period pollution levels can be obtained from (29) with $\delta=0$.
} 
The above delegated incentive mechanism with two specific interest groups (DIM2) is to be compared with a constitutional pooling mechanism that determines a unique welfare-maximizing pollution abatement level as a function of $\lambda$ but is common to all firms and environmentalists (or specific values of $\beta$ and $\theta$ ) and common to all majorities in power, that is, a CPM2 regulation. ${ }^{17}$ This comparison creates a real tradeoff between the simplicity of the constitution and the distortions created by the political delegation and the use of separating mechanisms by majorities even in the simple limit case of $\operatorname{var}(\lambda)=0$. The same type of results would be obtained by comparing the performance of the DIM2 with reelection concerns to that of the CIM, characterized in Section 4, when $\operatorname{var}(\lambda)>0$. The latter can be characterized as follows:

$$
\max _{d} W(d)=S-(1+\lambda)(E \beta(K-d)+E \theta V(d))-\lambda \mu \Delta \theta V(d)-\lambda \nu \Delta \beta(K-d)
$$

yielding

$$
\left(E \theta+\frac{\lambda}{1+\lambda} \mu \Delta \theta\right) V^{\prime}(\hat{d})=\left(E \beta+\frac{\lambda}{1+\lambda} \nu \Delta \beta\right),
$$

leading to

$$
E_{\lambda} W(\hat{d})
$$

The use of sophisticated delegated incentive schemes (DIM2) leads to two additional sources of distortions. First, campaign contributions are losses from a welfare point of view, and second, incentive distortions are reinforced. In a situation where the CPM2 scheme given by (32) is dominated in the static case by a DIM2 scheme, ${ }^{18}$ we may expect that it will dominate the latter for $g, \zeta$ or $\delta$ large enough. Figure 2 provides such an example. Curve $A$ illustrates the basic case $(\underline{\beta}=1, \bar{\beta}=1.5, \underline{\theta}=1, \bar{\theta}=1.5)$ in which, for large-enough values of $\delta$, the CPM2 scheme dominates the sophisticated DIM2 scheme. Curve B illustrates the same basic case except that $\bar{\beta}=1.7$; it shows that as the informational asymmetry $\Delta \beta$ is increased, the domination of the CPM2 scheme occurs for values of $\delta$ larger than 5.35. Curve $C$ illustrates the same basic case except that $\bar{\theta}=1.7$; it shows again that as the informational asymmetry $\Delta \theta$ is increased, the domination of the CPM2 scheme occurs for values of $\delta$ larger than 7.15.

In this context, the emergence of sophisticated delegated incentive mechanisms (DIM2) would therefore be associated with decreases in $\delta$, a measure of the desire of politicians to remain in power over time, with decreases in $g$, a measure of the importance of campaign contributions in the electoral process, and with decreases in $\zeta$, a measure of the willingness of agents to make campaign contributions out of their informational rents. Hence, the long-term objectives of politicians, together with the private financing of electoral campaigns, favor simple command and control schemes over more sophisticated delegated separating incentive mechanisms.

This negative effect of reelection concerns would be mitigated by a reputation effect if taxpayers punish politicians who pursue excessively their private agendas. This reputation effect would appear if, for instance, the reelection probability of a given majority depended also on the difference between its chosen menu of pollution levels

${ }^{17}$ The pure effect of the discount factor $\delta$ on the emergence of an incentive mechanism could be analyzed, in light of Proposition 2, by comparing DIM2 and DPM2, which are both influenced by $\delta$.

${ }^{18}$ The static regulation values for the CPM2 can be obtained from (29) with $\delta=0$.

O RAND 1999. 
FIGURE 2

THE DIFFERENTIAL EXPECTED WELFARE

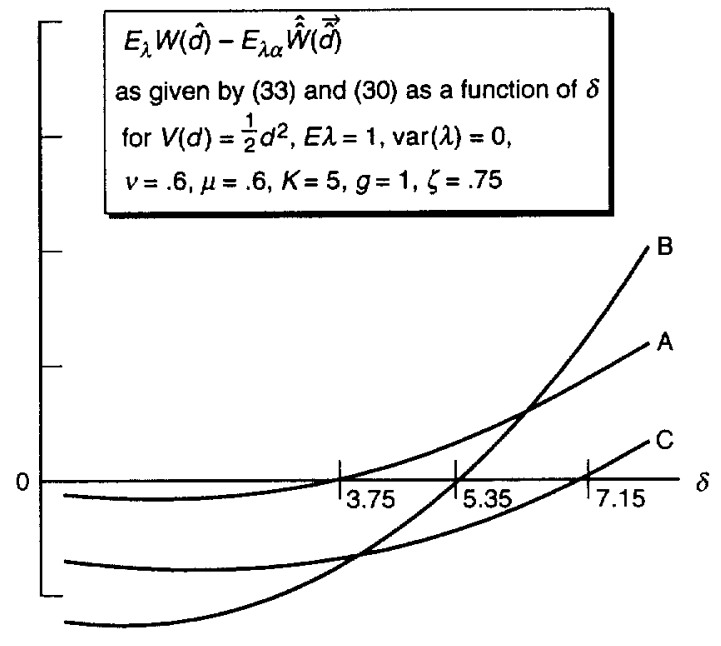

and the policy that would maximize social welfare. When in power, a majority would trade off in the first period the pursuit of its first-period gain and the impact of this pursuit on the probability of being reelected in the second period. Reelection considerations would then lead to conflicting influences. If pursuing excessively private agendas today is costly for the next election (through reputation effects and a better social control), then more sophisticated environmental policies may emerge as socially optimal. On the other hand, if the campaign contributions favoring reelection are important (large $g$ ) and significantly related (large $\zeta$ ) to the informational rents of the various interest groups, politicians are led to greater distortions to favor even more the interest groups supporting them. The presence of multiple interest groups may therefore transform valuable reforms toward delegated incentive mechanisms into undesirable reforms if these powerful mechanisms raise the stake of political conflicts, generating additional distortions.

\section{Conclusion}

- We have interpreted the political economy of environmental policy as an analysis of the economic implications of politicians' discretion in pursuing he private agendas of their electoral base: some voters are more concerned than others by pollution, some voters have stakes in the informational rents of the polluting firms.

Sophisticated environmental policy depends on nonverifiable variables that cannot be contracted upon in the constitution. So it must be delegated to politicians, creating an incentive problem when politicians' motivations are to stay in power by pleasing to a certain degree a majority of voters rather than by strictly maximizing social welfare. In this article we have studied the severity of this incentive proble:n. We have shown that the larger the social cost of public funds is (larger $E \lambda$ ) and the greater the variability of economic variables $(\operatorname{var}(\lambda), \Delta \beta, \Delta \theta)$ is, the more valuable flexibility is and therefore the greater the delegation of authority to politicians should be. However, the thinner the majorities are (the lower $\alpha^{*}$ is) or the larger the informational rents are (the larger $\nu$ and/or the larger $\mu$ are), the more the politicians' objectives are biased away from 
maximizing social welfare, providing a justification of cruder environmental policies that leave them less discretion.

The reelection mechanism we considered here depends solely on campaign contributions modelled as a given percentage of rents. When this is added to the waste of campaign contributions themselves, it favors giving up sophisticated policies that become costly political stakes. In this case, a longer-term view in politics (larger $\delta$ ) does not favor the emergence of sophisticated market-based or incentive mechanisms.

The approach developed in this article could be extended to other types of social and economic regulations. It should also be broadened by considering more detailed and realistic electoral processes and by introducing various institutions (bureaucracy, courts, etc.) that mitigate the incentive problems associated with the delegation of public policy responsibilities to political majorities. (See in particular Breyer (1993) and Pollak (1995).)

\section{Appendix}

- Proofs of Propositions 1-3 follow.

Proof of Proposition 1. To compare the two schemes, DPM and DIM, we first note that the two expected welfare functions evaluated at $\bar{\beta}=\beta$ are equal (equations (7), (8), (11), and (12) all give the same values) and that their first derivatives with respect to $\bar{\beta}$ evaluated at $\bar{\beta}=\underline{\beta}$ are negative and equal. Hence, we compare the DPM and DIM schemes by computing the second derivatives of the expected social welfare with respect to $\bar{\beta}$ at $\bar{\beta}=\underline{\beta}$. Consider first the case of the DIM scheme, where separating incentive mechanisms are chosen by the political majorities. Social welfare when majority 1 decides, $W\left(\underline{d}_{1}, \bar{d}_{1}\right)$, can be written from (1) and (4) as

$$
W\left(\underline{d}_{l}, \bar{d}_{1}\right)=\frac{W^{\prime}\left(\underline{d}_{1}, \bar{d}_{1}\right)}{\alpha^{*}}+\nu \Delta \beta\left(K-\bar{d}_{1}\right)
$$

where $W^{\prime}(\cdot, \cdot)$ is the objective function of majority 1 . Using the envelope theoren for $W^{\prime}\left(\underline{d}_{1}, \bar{d}_{1}\right)$, we have

$$
\frac{d W\left(\underline{d}_{1}, \bar{d}_{1}\right)}{d \bar{\beta}}=-(1+\lambda-\nu)\left(K-\bar{d}_{1}\right)-\nu \Delta \beta \frac{d \bar{d}_{1}}{d \bar{\beta}},
$$

where from (7),

$$
\frac{d \bar{d}_{1}}{d \bar{\beta}}=\frac{1+\lambda}{(1-\nu) V^{\prime \prime}\left(\bar{d}_{1}\right)}
$$

and therefore

$$
\frac{d^{2} W\left(\underline{d}_{1}, \bar{d}_{1}\right)}{d \bar{\beta}^{2}}=\frac{(1+\lambda-2 \nu)(1+\lambda)}{(1-\nu) V^{\prime \prime}\left(\bar{d}_{1}\right)}
$$

Similarly, when majority 2 decides, we have

$$
W\left(\underline{d}_{2}, \bar{d}_{2}\right)=\frac{W^{2}\left(\underline{d}_{2}, \bar{d}_{2}\right)}{\alpha^{*}}+\left(1-\frac{1}{\alpha^{*}}\right) \nu \Delta \beta\left(K-\bar{d}_{2}\right),
$$

yielding

$$
\frac{d W\left(\underline{d}_{2}, \bar{d}_{2}\right)}{d \bar{\beta}}=-(1+\lambda-\nu)\left(K-\bar{d}_{2}\right)-\left(1-\frac{1}{\alpha^{*}}\right) \nu \Delta \beta \frac{d \bar{d}_{2}}{d \bar{\beta}}
$$

where from (8)

c) RAND 1999. 


$$
\frac{d \bar{d}_{2}}{d \bar{\beta}}=\frac{1+\lambda-\nu / \alpha^{*}}{(1-\nu) V^{\prime \prime}\left(\bar{d}_{2}\right)}
$$

and therefore

$$
\frac{d^{2} W\left(\underline{d}_{2}, \bar{d}_{2}\right)}{d \bar{\beta}^{2}}=\frac{\left(1+\lambda-\nu / \alpha^{*}\right)}{(1-\nu) V^{\prime \prime}\left(\bar{d}_{2}\right)}\left(1+\lambda+\frac{\nu}{\alpha^{*}}-2 \nu\right) .
$$

Hence the expected second derivative at $\bar{\beta}=\underline{\beta}$ (implying that $\bar{d}_{1}=\underline{d}_{1}=(1+\lambda) \underline{\beta}$ ) in the case of the DIM (assuming that each majority is in power half the time) is given by

$$
\left.\frac{d^{2} E_{\lambda \alpha} W(\underline{d}, \bar{d})}{d \bar{\beta}^{2}}\right|_{\bar{\beta}-\underline{B}}=\frac{\nu^{2}\left(\frac{\alpha^{*}-\frac{1}{2}}{\alpha^{* 2}}\right)+1-2 \nu+2(1-\nu) E \lambda+(E \lambda)^{2} \cdots \operatorname{var}(\lambda)}{(1-\nu) V^{\prime \prime}\left(d^{0}\right)},
$$

where $V^{\prime}\left(d^{0}\right)=(1+\lambda) \beta$.

Consider now the DPM scheme, where the political majorities are restricted to choosing a single abatement level as a function of $\lambda$. We obtain from (11) and (12)

$$
\left.\frac{d d_{1}}{d \bar{\beta}}\right|_{\bar{\beta}=\underline{\beta}}=\frac{1+\lambda}{V^{\prime \prime}\left(d^{0}\right)}
$$

and

$$
\left.\frac{d d_{2}}{d \bar{\beta}}\right|_{\bar{\beta}=\underline{\beta}}=\frac{1+\lambda-\frac{\nu}{\alpha^{*}}}{V^{\prime \prime}\left(d^{0}\right)}
$$

The social welfare when majority $l$ is in power is given by

$$
W\left(d_{1}\right)=\frac{W^{\prime}\left(d_{1}\right)}{\alpha^{*}}+\nu \Delta \beta\left(K-d_{1}\right)
$$

and, similarly, the social welfare when majority 2 is in power is given by

$$
W\left(d_{2}\right)=\frac{W^{2}\left(d_{2}\right)}{\alpha^{*}}+\left(1-\frac{1}{\alpha^{*}}\right) \nu \Delta \beta\left(K-d_{2}\right)
$$

Hence,

$$
\frac{d W\left(d_{1}\right)}{d \bar{\beta}}=-(1+\lambda-\nu)\left(K-d_{1}\right)-\nu \Delta \beta \frac{d d_{1}}{d \bar{\beta}}
$$

and

$$
\frac{d W\left(d_{2}\right)}{d \bar{\beta}}=-(1+\lambda-\nu)\left(K-d_{2}\right)-\left(1-\frac{1}{\alpha^{*}}\right) \nu \Delta \beta \frac{d d_{2}}{d \bar{\beta}}
$$

We therefore obtain

$$
\left.\frac{d^{2} W\left(d_{1}\right)}{d \bar{\beta}^{2}}\right|_{\bar{\beta}=\underline{\beta}}=(1+\lambda-2 \nu) \frac{(1+\lambda)}{V^{\prime \prime}\left(d^{0}\right)}
$$

and

ce RAND 1999. 


$$
\left.\frac{d^{2} W\left(d_{2}\right)}{d \bar{\beta}^{2}}\right|_{\bar{\beta}=\underline{\beta}}=\left(1+\lambda+\frac{\nu}{\alpha^{*}}-2 \nu\right) \frac{\left(1+\lambda-\frac{\nu}{\alpha^{*}}\right)}{V^{\prime \prime}\left(d_{0}\right)} .
$$

Hence the expected second derivative at $\bar{\beta}=\underline{\beta}$ in the case of a DPM scheme (assuming again that each majority is in power half the time) is given by

$$
\left.\frac{d^{2} E_{\lambda a} W(d)}{d \bar{\beta}^{2}}\right|_{\bar{\beta}-\underline{B}}=\frac{\nu^{2}\left(\frac{\alpha^{*}-\frac{1}{2}}{\alpha^{* 2}}\right)+1-2 \nu+2(1-\nu) E \lambda+(E \lambda)^{2}+\operatorname{var}(\lambda)}{V^{\prime \prime}\left(d^{0}\right)} .
$$

Therefore, the second derivative of the expected social welfare under the DPM scheme is $(1-v)$ times the second derivative of the expected social welfare under the DIM scheme as giver above. Those derivatives are of the sign of the numerator, which is positive if and only if (14) holds. If $\operatorname{var}(\lambda)>H(\cdot)$, the DIM dominates the DPM for $\bar{\beta}$ close to $\underline{\beta}$ and vice-versa if $\operatorname{var}(\lambda)<H(\cdot)$. Q.E.D.

Proof of Proposition 2. We want to compare the expected welfare of each majority under a DPM imposed by the constitution and under a DIM to determine the eagerness of each majority to support the latter constitutional rule. So we want to compare in per-capita terms

$$
E_{\lambda n} W^{\prime}(d)-E_{\lambda r} W^{1}(\underline{d}, \bar{d})
$$

and

$$
E_{\lambda \alpha} W^{2}(d)-E_{\lambda \mu} W^{2}(\underline{d}, \bar{d})
$$

for $\bar{\beta}$ close to $\beta$. First note that both differences and their first derivatives with respect to $\bar{\beta}$ vanish at $\Delta \beta=0$. So we consider second derivatives. Straightforward computations (the proof follows steps similar to those in the proof of proposition 1; details are available from the authors) lead to

$$
E_{\lambda u} \frac{\partial^{2} W^{1}(d) / \alpha^{*}}{\partial \bar{\beta}^{2}}-E_{\lambda \alpha} \frac{\partial^{2} W^{1}(\underline{d}, \bar{d}) / \alpha^{*}}{\partial \bar{\beta}^{2}} \text { if and only if } \operatorname{var}(\lambda)>H^{1}\left(\nu, \alpha^{*}, E \lambda\right)
$$

and, similarly,

$$
E_{\lambda \alpha} \frac{\partial^{2} W^{2}(d) / \alpha^{*}}{\partial \bar{\beta}^{2}}-E_{\lambda \alpha} \frac{\partial^{2} W^{2}(\underline{d}, \bar{d}) / \alpha^{*}}{\partial \bar{\beta}^{2}} \text { if and only if } \operatorname{var}(\lambda)>H^{2}\left(\eta, \alpha^{*}, E \lambda\right) .
$$

Proof of Proposition 3. Clear from the text.

\section{References}

Barnett, A.H. "The Pigouvian Tax Rule Under Monopoly." American Economic Review, Vol. 70 (1980), pp. 1037-1041.

BARON, D.P. "Regulation of Prices and Pollution Under Incomplete Information." Journal of Public Economics, Vol. 28 (1985a), pp. 211-231.

_. "Noncooperative Regulation of a Nonlocalized Externality." RAND Joumal of Economics, Vol. 16 (1985b), pp. 553-568.

- AND Myerson, R.B. "Regulating a Monopolist with Unknown Costs." Econometrica, Vol. 50 (1982), pp. $911-930$.

Baumol, W.J. AND BRAdFord, D.F. "Detrimental Externalities and Non-Convexity of the Production Set." Economica, Vol. 39 (1972), pp. 160-176.

Вонм, P. Deposit-Refund Systems: Theory and Applications to Environmental, Conservation, and Consumer Policy. Washington, D.C.: Johns Hopkins University Press, 1981.

Boyer, M. "Les effects de la réglementation." Canadian Public Policy / Analyse de' Politiques, Vol. 4 (1979), pp. $469-474$.

RAND 1999 
AND J.-J. LAFFont "Environmental Protection, Producer Insolvency and Lender Liability." In A. Xepapadeas, ed., Economic Policy for the Environment and Natural Resources. Brookfield, Vt.: Edward Elgar, 1996.

— AND —. "Environmental Risks and Bank Liability." European Economic Review, Vol. 41 (1997), pp. 1427-1459.

Bramhall, D.F. and Milis, E.S. "A Note on the Asymmetry Between Fees and Payments." Water Resources Research, Vol. 2 (1966), pp. 615-616.

Breyer, S.G. Breaking the Vicious Circle: Toward Effective Risk Regulation. Cambridge, Mass.: Harvard University Press, 1993.

Buchanan, J.M. “External Diseconomies, Corrective Taxes, and Market Structure." American Economic Review, Vol. 59 (1969), pp. 174-177.

- and Tullock, G. "Polluters' Profits and Political Response: Direct Control Versus Taxes." American Economic Review; Vol. 65 (1975), pp. 139-147

Coelho, P.R.P. "Polluters' Profits and Political Response: Direct Control Versus Taxes: Comment." American Economic Review, Vol. 66 (1976), pp. 976-978.

Crocker, T. "The Structuring of Atmospheric Pollution Control Systems." In H. Wolozin, ed., The Economics of Air Pollution. New York: W.W. Norton, 1966.

Cropper, M.L. AND OATes, W. "Environmental Economics: A Survey." Journal of Economic Literature, Vol. 30 (1992), pp. 675-740.

DaLes, J.H. "Land, Water and Ownership." Canadian Journal of Economics, Vol. 1 (1968a), pp. 797-804.

- Pollution, Property and Prices. Toronto: University of Toronto Press, 1968.

Dasgupta, P., Hammond, P., AND Maskin, E. "On the Imperfect Information and Optimal Pollution Control." Review of Economic: Studies, Vol. 47 (1980), pp. 857-860.

Dewees, D.N. "Instrument Choice in Environmental Policy." Economic Inquiry, Vol. 21 (1983), pp. 53-71.

- AND Sims, W.A. "The Symmetry of Effluent Charges and Subsidies for Pollution Control." Canadian Journal of Economics, Vol. 9 (1976), pp. 323-331.

Guesnerie, R. ANd LAfFont, J.-J. "A Complete Solution to a Class of Principal-Angent Problems with an Application to the Control of a Self-Managed Firm." Journal of Public Economics, Vol, 25 (1984), pp. 329-369.

Gupta, S., Van Houtven, G., And Cropper, M. "Paying for Permanence: An Análysis of EPA's Cleanup Decisions at Superfund Sites." RAND Journal of Economics, Vol. 27 (1996), pp. 563-582.

HaHN, R.W. "The Political Economy of Environmental Regulation: Towards a Unifying Framework." Public Choice, Vol. 65 (1990), pp. 21-47.

- AND MCGARTLAND, A.M. "The Political Economy of Instrument Choice: An Examination of the U.S. Role in Implementing the Montreal Ptotocol." Northwestern University Law Review, Vol. 83 (1989), pp. 592-611.

Holmström, B. "On the Theory of Delegation." In M. Boyer and R.E. Kihlstrom. eds., Bayesian Models in Economic Theory. New York: North-Holland, 1984

Jones, L.P., Tandon, P., And Vogelsang, I. Selling Public Enterprises. Cambridge, Mass.: Mit Press, 1990.

Kamien, M.L., Schwartz, N.L., and Dolbear, F.T. "Asymmetry Between Bribes and Charges." Water Resources Research, Vol. 2 (1966), pp. 147-157.

KNEESE, A.V. AND Bower, B.T. Managing Water Quality: Economics, Technology, Institutions. Baltimore: Johns Hopkins University Press, 1968.

LAfFont, J.-J. "Regulation of Pollution with Asymmetric Information." In C. Dosi and T. Tomasi, eds., Nonpoint Source Pollution Regulation: Issues and Analysis. Dordrecht: Kluwer Academic, 1994.

-. "Industrial Policy and Politics." International Journal of Industrial Organization, Vol. 14 (1996), pp. 1-27.

- And Tirole, J. A Theory of Incentives in Procurement and Regulation. Cambridge, Mass.: MIT Press, 1993.

LEE, D.R. "Efficiency of Pollution Taxation and Market Structure." Journal of Environmental Economics and Management, Vol. 2 (1975), pp. 69-72.

LEwIS, T.R. "Protecting the Environment When Costs and Benefits Are Privately Known." RAND Journal of Economics, Vol. 27 (1996), pp. 819-847.

LoEB, M. AND MAGAT, W.A. "A Decentralized Method for Utility Regulation." Joumal of Law and Economics, Vol. 22 (1979), pp. 399-404.

MCCubrins, M.D., Noll, R.G., and Weingast, B.R. "Structure and Process, Politics and Policy: Administrative Arrangements and the Political Control of Agencies." Virginia Law Review, Vol. 75 (1989), pp. $431-482$.

NoLl, R. "The Political Foundations of Regulatory Policy." Journal of Institutional and Theoretical Economics, Vol. 139 (1983), pp. 377-404.

RAND 1999 
POLlAK, R.A. "Regulating Risks." Journal of Economic Literature, Vol. 33 (1995i), pp. 179-191.

Roberts, M.J. And SFence, M. "Effluent Charges and Licenses Under Uncertainty." Journal of Public Economics, Vol. 5 (1976), pp. 193-208.

Segerson, K. "Liability and Penalty Structures in Policy Design." In D.W. Bromley, ed., Handbook of Environmental Economics. Cambridge, Mass.: Basil Blackwell, 1995.

- "Issues in the Choice of Environmental Policy Instruments." In J.B. Braden, H. Folmer, and T.S. Ulen, eds., Environmental Policy with Political and Economic Integration Brookfield, Vt.: Edward Elgar, 1996.

Starretr, D.A. "Fundamental Nonconvexities in the Theory of Externalities." Journal of Economic Theory. Vol. 4 (1972), pp.180-199.

WeitzMan, M.L. "Prices vs. Quantities." Review of Economic Siudies, Vol. 41 (1975), pp. 477-491.

YoHe, G.W. "Polluter's Profits and Political Response: Direct Control Versus Taxes: Comment." American Economic Review, Vol. 66 (1976), pp. 981-982. 